\title{
Aerosol Delivery Through an Adult High-Flow Nasal Cannula Circuit Using Low-Flow Oxygen
}

\author{
Yasmin M Madney, Maha Fathy, Ahmed A Elberry, Hoda Rabea, and Mohamed EA Abdelrahim
}

BACKGROUND: There has been a growing trend toward delivering aerosolized medications using high-flow nasal cannula (HFNC). In some cases, patients who do not require high-flow oxygen to maintain adequate oxygenation may benefit from aerosol delivery while receiving low-flow oxygen via HFNC. The objective of this study was to quantify and compare the relative pulmonary and systemic delivery of salbutamol, with 2 different nebulizers, in patients with COPD receiving low-flow oxygen therapy through an HFNC. METHODS: Subjects were randomized to receive study doses of $5 \mathrm{mg}$ salbutamol nebulized by either a jet nebulizer or a vibrating mesh nebulizer with a T-piece or spacer on days 1, 3, and 5 of admission. Subjects using the large spacer also received 2 puffs (100 $\mu \mathrm{g}$ each) of salbutamol via a pressurized metered-dose-inhaler prior to the nebulizer dose. Urinary salbutamol excretion $30 \mathrm{~min}$ post-inhalation and pooled samples of urinary salbutamol excretion up to $24 \mathrm{~h}$ post-inhalation were measured. On day 2 , ex vivo studies were performed with salbutamol collected on filters placed between the HFNC and nebulizer, with drug eluted from filters and analyzed to determine inhaled dose. RESULTS: Twelve subjects (6 females), age $51.3 \pm 11.2 \mathrm{y}$, were included. The vibrating mesh nebulizer demonstrated higher urinary salbutamol excretion at $30 \mathrm{~min}$ and $24 \mathrm{~h}$ post-inhalation compared to a jet nebulizer $(P=.001$ and $P=.02$, respectively). No significant difference was found between the T-piece and large-spacer configurations, even though the spacer provided a significantly larger emitted aerosol dose at the opening of the HFNC $(P=.002)$. CONCLUSIONS: Aerosolized medication could be efficiently combined with low-flow oxygen, via HFNC, in COPD subjects without the need to interrupt the gas supply. The vibrating mesh nebulizer delivered larger doses to subjects compared to the jet nebulizer. However, there was no benefit of using the large spacer with HFNC in low-flow delivery, because the small inner diameter of the HFNC does not allow larger aerosol droplet sizes (preserved by the spacer) to reach the subject. Key words: nebulizers; large spacer; HFNC; inhalation therapy; nasal cannula; low-flow oxygen. [Respir Care 2019;64(4):453-461. () 2019 Daedalus Enterprises]

\section{Introduction}

Oxygen supplementation is one of the most commonly prescribed therapies in hospitals, ${ }^{1,2}$ and it is a mainstay of

Ms Madney and Drs Rabea and Abdelrahim are affiliated with the Clinical Pharmacy Department, Faculty of Pharmacy, Beni-Suef University, Beni-Suef, Egypt. Dr Fathy is affiliated with the Respiratory Department, Faculty of Medicine, Beni-Suef University, Beni-Suef, Egypt. Dr Elberry is affiliated with the Clinical Pharmacology Department, Faculty of Medicine, Beni-Suef University, Beni-Suef, Egypt. Dr Abdelrahim is also affiliated with the Clinical Pharmacy Department, Faculty of Pharmacy, Modern University for Technology and Information, Cairo, Egypt.

Dr Abdelrahim discloses a relationship with Aerogen. The other authors have disclosed no conflicts of interest. resuscitation in acutely ill patients. ${ }^{2}$ In hypoxic patients with COPD, long-term oxygen therapy together with pulmonary rehabilitation are crucial interventions that increase life expectancy and improve quality of life. ${ }^{3,4}$

In clinical practice, nasal cannulae are the most commonly used delivery method for supplemental oxygen. ${ }^{5-8}$ There are limitations associated with low-flow oxygen through cannulae, although these limitations usually do

Correspondence: Mohamed EA Abdelrahim PhD, Faculty of Pharmacy, Beni-suef University, Salah Eldin street, Beni-suef, Egypt. E-mail: mohamedemem9@yahoo.com.

DOI: $10.4187 /$ respcare. 06345 
not have clinical consequences when the supplemental oxygen flow is adequate to correct hypoxemia ${ }^{5}$ and meet a patient's oxygen requirements at rest or with limited activity. ${ }^{6}$ However, increasing attention is being paid to humidified high-flow nasal cannula (HFNC) oxygen therapy. ${ }^{7}$ These nasal cannulae are designed to allow higher flows and prevent delivery of a gas jet directly onto mucosal surfaces. ${ }^{8}$

Moreover, devices used to deliver oxygen are classified into low-, intermediate- (eg, air-entrainment mask), and high-flow devices. The conventional low- and intermediate-flow devices have several disadvantages, including variable $\mathrm{F}_{\mathrm{IO}_{2}}{ }^{9}$ and inadequately warmed or humidified gas, which lead to patient discomfort. ${ }^{3}$ Consequently, there is a clinical trend toward using high-flow devices that allow adjustment of $\mathrm{F}_{\mathrm{IO}_{2}}$ independently of gas flow to fall between $0.21-1.0^{3,10,11}$ and, more importantly, that deliver a sufficiently heated and humidified medical gas. ${ }^{12}$

For patients suffering an exacerbation of COPD, respiratory support can be preceded by noninvasive ventilation (NIV) with a face mask or HFNC. ${ }^{10}$ However, HFNC is better tolerated than NIV and can deliver a wider range of $\mathrm{F}_{\mathrm{IO}_{2}}$ as required. ${ }^{10}$ In addition, HFNC offers additional physiological benefits, such as improved tissue oxygenation, improved functional residual capacity, decreased nasopharyngeal resistance, and flushing of pharyngeal dead space of $\mathrm{CO}_{2}$, which make HFNC an attractive alternative modality of respiratory support in COPD patients. ${ }^{1,9,13-15}$

To facilitate the delivery of inhaled medications during HFNC, there are 2 possible approaches. One approach is to abruptly remove the patient from the high-flow circuit and then administer the inhaled drug with either a nebulizer or a pressurized metered-dose inhaler (pMDI) with spacer. Although this approach potentially allows adequate drug delivery, it may contribute to worsening the patient's respiratory status due to the temporary removal of supplemental oxygen. Another approach is to deliver the inhaled medication through HFNC, ${ }^{16-19}$ thereby ensuring drug delivery without interrupting supplemental oxygen. ${ }^{20-22}$ In addition, nasal aerosol delivery is advantageous over oral inhalation because it may improve both subject comfort and compliance by using a cannula to administer doses, either frequently or over long durations. ${ }^{11,23}$

How then to combine aerosol delivery with the HFNC system while maximizing aerosol delivery to the lungs in COPD subjects? Previous in vitro studies that combined aerosol delivery with HFNC systems found that the delivered dose is inversely proportional to the gas flow and directly proportional to the cannula size. ${ }^{16,18,19,22-25}$

These findings were previously validated by our in vitro study, ${ }^{26}$ which found significantly improved delivered doses and aerodynamic aerosol characteristics for both vibrating mesh nebulizers and jet nebulizers in a HFNC

\section{QUICK LOOK}

\section{Current knowledge}

There is a growing trend toward delivering aerosol medications via high-flow nasal cannula (HFNC). Previous bench studies that evaluated aerosol delivery via HFNC systems found that the delivered dose is inversely proportional to the gas flows and directly proportional to the cannula size.

\section{What this paper contributes to our knowledge}

Drug nebulization could be efficiently combined with HFNC therapy using low-flow oxygen in subjects with COPD with a history of exacerbations, without the need to temporarily halt the gas supply. A vibrating mesh nebulizer delivered a larger dose of drug to subjects compared to a jet nebulizer. There is no measurable benefit to using a spacer in HFNC-mediated aerosol delivery.

circuit with adult nasal cannula with low oxygen flow (5 L/min), whereas pMDIs with spacers delivered negligible amounts of salbutamol. Our previous study also examined the performance of the large spacer, which facilitates delivery with both a pMDI and a vibrating mesh nebulizer. ${ }^{26}$ The manufacturer of this device recommends 1-2 prophylactic bronchodilator puffs from the pMDI before starting nebulizer delivery to improve dosing; we were unable to measure this as a possible benefit due to that study's limitations.

The present in vivo study used low oxygen flow $(5 \mathrm{~L} / \mathrm{min})$ in a HFNC circuit using an adult nasal cannula to compare both the pulmonary and systemic bioavailability of jet nebulizer and vibrating mesh nebulizer delivery with their standard T-pieces, and pMDI and vibrating mesh nebulizer delivery via a large spacer in subjects with COPD.

\section{Methods}

\section{Participants}

The study was approved by the Beni-Suef University Hospital Research Ethics Committee. Written informed consent was obtained from all subjects. A convenience sample of subjects, diagnosed with COPD and previously admitted to the respiratory unit with an exacerbation requiring respiratory support, were recruited into this study. All subjects were prescribed nebulized salbutamol and ipratropium bromide on alternating days upon admission. Subjects were excluded from this study if they had participated in any other research study during the previous 


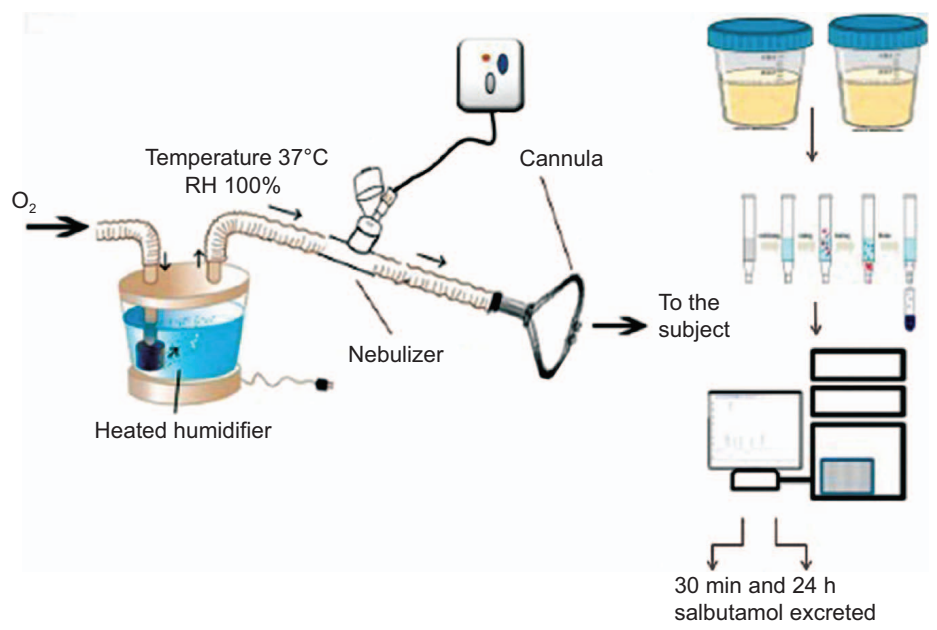

Fig. 1. Schematic design of an in vivo setting showing the positions of the aerosol generator within the high-flow nasal cannula circuit and measurement of urinary salbutamol excretion. $\mathrm{RH}=$ relative humidity.

6 months, had a known hypersensitivity to salbutamol or ipratropium bromide, had a systolic blood pressure $<100 \mathrm{~mm} \mathrm{Hg}$, or had severe renal dysfunction defined as an estimated glomerular filtration rate $<20 \mathrm{~mL} / \mathrm{min}^{13}$

\section{Circuit Description}

A heated humidifier (MR810, Fisher \& Paykel Healthcare, Auckland, New Zealand) which can deliver gas flows of 1-60 L/min with adjusted $\mathrm{F}_{\mathrm{IO}_{2}}$ of $0.21-1.00^{14}$ while the gas is heated $\left(37^{\circ} \mathrm{C}\right)$ and humidified $(100 \%)$ was connected to an adult-sized nasal cannula (Jiaxing Sim Medical, Zhejiang, China) and then to the subject. The nebulizer with T-piece or spacer apparatus was positioned downstream of the humidifier, as shown in Figure 1, and the oxygen flow within the HFNC circuit was set to $5 \mathrm{~L} / \mathrm{min}$ for all tests.

\section{Aerosol Delivery Devices}

As shown in Figure 2, either a vibrating mesh nebulizer (Aerogen Solo, Aerogen, Galway, Ireland) or a jet nebulizer (Oxycare, Ceren Üretim A.S., Istanbul, Turkey) was tested with a large spacer (Combihaler Laboratoire Protec'Som, Valognes, France) in this study. ${ }^{26}$ Salbutamol ( $5 \mathrm{mg} / \mathrm{mL}$; Farcolin Respirator solution, Pharco Pharmaceuticals, Alexandria, Egypt) was delivered using either the jet nebulizer or the vibrating mesh nebulizer connected to the HFNC system using the manufacturer-supplied Tpieces with an oxygen flow of $5 \mathrm{~L} / \mathrm{min}\left(\mathrm{F}_{\mathrm{IO}_{2}}=1.0\right)$. The vibrating mesh nebulizer was also tested connected to the large spacer in combination with a pMDI (Ventolin Evohaler, GlaxoSmithKline, Cairo, Egypt) as shown in Figure 2. Two $100 \mu \mathrm{g}$ puffs of salbutamol were delivered to the subject via pMDI, followed by $1 \mathrm{~mL}(5 \mathrm{mg})$ salbutamol using the vibrating mesh nebulizer per manufacturer recommendations.
In all cases, nebulization continued until the aerosol was no longer visible emanating from the vibrating mesh nebulizer and to sputtering for the jet nebulizer.

\section{Study Design}

Salbutamol administration was withheld before the beginning of the study for at least $12 \mathrm{~h}$. During the study period, ipratropium bromide solution $(250 \mu \mathrm{g} / \mathrm{mL}$, Atrovent Inhalation Solution, Boehringer Ingelheim, Egypt) was prescribed to the subjects instead of their regular salbutamol. High-performance liquid chromatography (HPLC) analysis of the subject's urine was utilized to differentiate between ipratropium and salbutamol. Subjects were randomly selected to receive their usual salbutamol study dose either by vibrating mesh nebulizer, jet nebulizer, or vibrating mesh nebulizer with a large-spacer on days 1,3 , and 5 of the study. Approximately 15 min before each study dose, subjects were asked to void their urine. Two urine samples were then taken from each subject, one at $30 \mathrm{~min}$ after the start of dosing and the other consisting of all urine produced over the next $24 \mathrm{~h}$. It was previously demonstrated that the concentration of salbutamol in urinary salbutamol excretion $30 \mathrm{~min}$ post-inhalation is a representative index of pulmonary salbutamol lung deposition, while the concentration found in urinary salbutamol excretion $24 \mathrm{~h}$ post-inhalation is an index of salbutamol systemic bioavailability. ${ }^{13,15}$

The volumes of urine (urinary salbutamol excretion $30 \mathrm{~min}$ post-inhalation and urinary salbutamol excretion $24 \mathrm{~h}$ postinhalation) were recorded, and the urine was assayed, using HPLC, to determine salbutamol concentration. Bambuterol hydrochloride was added as the internal standard to the collected urine samples. Salbutamol and bambuterol were extracted from urine samples using solid phase extraction. ${ }^{16}$ As shown in Figure 1, the eluent was then injected into the 

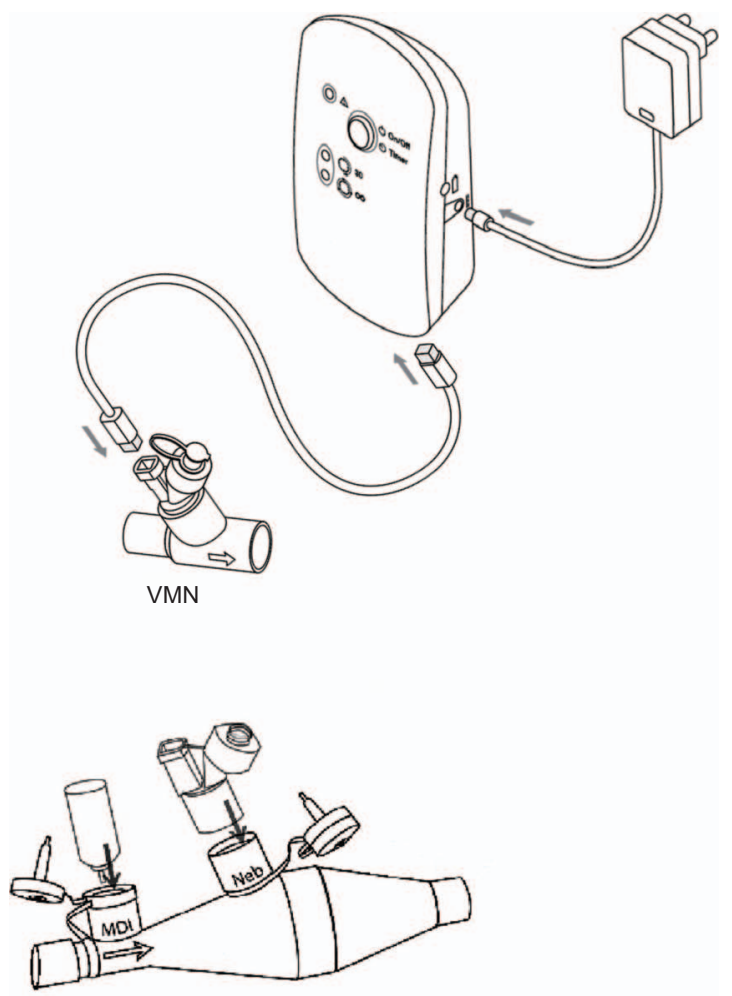

Larger spacer with pMDI and VMN

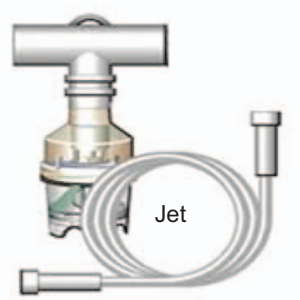

Fig. 2. Assembly of aerosol generators with its connections. VMN = vibrating mesh nebulizer; pMDI = pressurized metereddose inhaler.

HPLC system, which was composed of an ODS $5 \mu \mathrm{m}$ (4.6 $\times 250 \mathrm{~mm}$, ZORBAX Eclipse) C-18 HPLC column with a C-18 (ODS) guard column (4 mm $\times 3 \mathrm{~mm}$, Agilent). The mobile phase, composed of acetonitrile solution in water containing $0.1 \%$ orthophosphoric acid (90:10, v/v), was pumped through the columns at a flow of $1 \mathrm{~mL} / \mathrm{min}$. A $25-$ photodiode array detector was set at $220 \mathrm{~nm}$. The lower detection limit and lower quantification limit for salbutamol were 0.36 and $1.00 \mu \mathrm{g} / \mathrm{mL}$, respectively. ${ }^{17}$

\section{Ex Vivo Procedure}

On day 2, subjects received study doses via the same equipment as previously, but this time with a breathing filter (Filta-Guard, Intersurgical, Wokingham, United
Kingdom) placed between the nasal cannula and the nebulizer within the same HFNC circuit, as illustrated in Figure 3 , to collect the entire dose delivered to the cannula outlet. ${ }^{13}$ Because this setup would not deliver any bronchodilator to the subjects, they resumed their prescribed dose of ipratropium bromide. Drug collected on the filter was eluted to determine the emitted dose. The amount of drug deposited within the circuit was recovered by rinsing with the mobile phase, and then recovered sample was assayed with HPLC as described previously.

\section{Data Analysis}

Data were analyzed with a 1-way ANOVA test with the application of least significant difference correction to determine any difference between aerosol generators in the urinary salbutamol excretion 30 min post-inhalation, urinary salbutamol excretion $24 \mathrm{~h}$ post-inhalation, and emitted dose. All other data were expressed as mean \pm SD. Significance was defined as $P<.05$. All tests were performed using SPSS v17.0 (SPSS, Chicago, Illinois).

\section{Results}

\section{Subject Characteristics}

A convenience sample of 12 subjects completed the study (6 females). Their mean $\pm \mathrm{SD}$ age was $51.3 \pm 11.2 \mathrm{y}$, weight $83.5 \pm 11.2 \mathrm{~kg}$, and height $164.4 \pm 9.0 \mathrm{~cm}$.

\section{Urinary Salbutamol Excretion}

The mean \pm SD salbutamol amount $(\mu \mathrm{g})$ and salbutamol percentage of the nominal dose detected in both urinary salbutamol excretion 30 min post-inhalation and urinary salbutamol excretion $24 \mathrm{~h}$ post-inhalation for both vibrating mesh nebulizer and jet nebulizer are shown in Table 1, Figure 4, and Figure 5. The vibrating mesh nebulizer with $\mathrm{T}$-piece and spacer resulted in a $>2$-fold increase in the detected urinary salbutamol excretion percentage $30 \mathrm{~min}$ post-inhalation compared to the jet nebulizer ( $P=.001$ and $P=.012$, respectively), whereas the vibrating mesh nebulizer with T-piece trended higher than the vibrating mesh nebulizer with the spacer (Fig. 4). Similarly, urinary salbutamol excretion percentage 24 h postinhalation for the jet nebulizer was significantly lower than that for the vibrating mesh nebulizer with T-piece only or with the large spacer $(P=.02$ and $P=.003$, respectively). In contrast to urinary salbutamol excretion percentage 30 min post-inhalation, the vibrating mesh nebulizer with spacer resulted in higher urinary salbutamol excretion percentage $24 \mathrm{~h}$ post-inhalation than the vibrating mesh nebulizer with T-piece alone, but the difference was not significant (Fig. 5). 


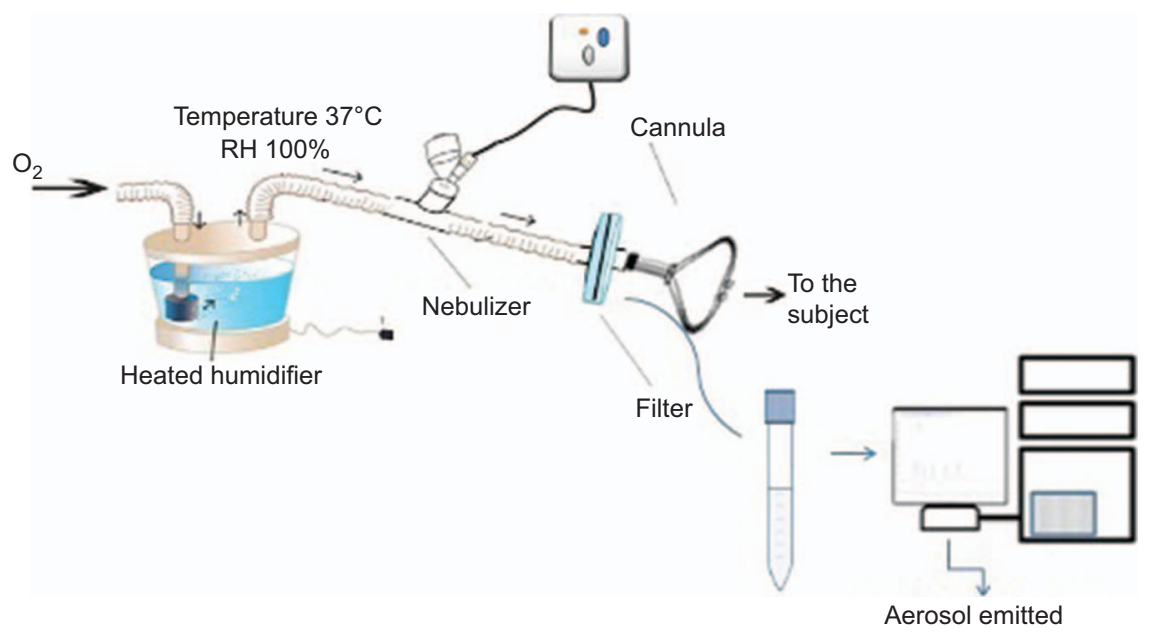

Fig. 3. Schematic design of ex vivo setting, showing the positions of the aerosol generator and the ex vivo filter within the high-flow nasal cannula circuit. $\mathrm{RH}=$ relative humidity.

Table 1. In Vivo and Ex Vivo Results of the Dose Delivered to Subjects Through HFNC

\begin{tabular}{|c|c|c|c|}
\hline & $\begin{array}{c}\text { Vibrating Mesh } \\
\text { Nebulizer with T-Piece }\end{array}$ & $\begin{array}{l}\text { pMDI and Vibrating Mesh } \\
\text { Nebulizer with Spacer }\end{array}$ & $\begin{array}{l}\text { Jet Nebulizer } \\
\text { with T-Piece }\end{array}$ \\
\hline \multicolumn{4}{|l|}{ In vivo } \\
\hline Urinary salbutamol excretion $30 \mathrm{~min}$ post-inhalation, $\mu \mathrm{g}$ & $50.6 \pm 19.7$ & $45.7 \pm 16.1$ & $26.4 \pm 10.8$ \\
\hline Urinary salbutamol excretion $30 \mathrm{~min}$ post-inhalation, $\%$ & $1.0 \pm 0.4 * \dagger$ & $0.9 \pm 0.3 *+$ & $0.5 \pm 0.2 * \dagger+$ \\
\hline Urinary salbutamol excretion $24 \mathrm{~h}$ post-inhalation, $\mu \mathrm{g}$ & $611.1 \pm 218.6$ & $707.5 \pm 270.4$ & $393.6 \pm 155.7$ \\
\hline Urinary salbutamol excretion $24 \mathrm{~h}$ post-inhalation, $\%$ & $12.2 \pm 4.4^{* \dagger}$ & $13.6 \pm 5.2 *+$ & $7.9 \pm 3.1 * \dagger+$ \\
\hline \multicolumn{4}{|l|}{ Ex vivo } \\
\hline Emitted dose, $\mu \mathrm{g}$ & $1,277.2 \pm 143.7$ & $1,657.2 \pm 308.9$ & $602 \pm 196.3$ \\
\hline Emitted dose, \% & $25.5 \pm 2.9^{*} \dagger$ & $31.9 \pm 5.9^{*}+$ & $12 \pm 3.9 * \dagger+$ \\
\hline $\begin{array}{l}\text { Data are presented as mean } \pm \text { SD. } \\
\text { HFNC }=\text { high-flow nasal cannula } \\
* \text { The difference is significant }(P<.05) \text {. } \\
\dagger \text { Comparison between vibrating mesh nebulizer and jet nebulizer. } \\
\begin{array}{l}\text { Comparison between spacer and jet nebulizer. } \\
\text { pMDI = pressurized metered-dose inhaler }\end{array}\end{array}$ & & & \\
\hline
\end{tabular}

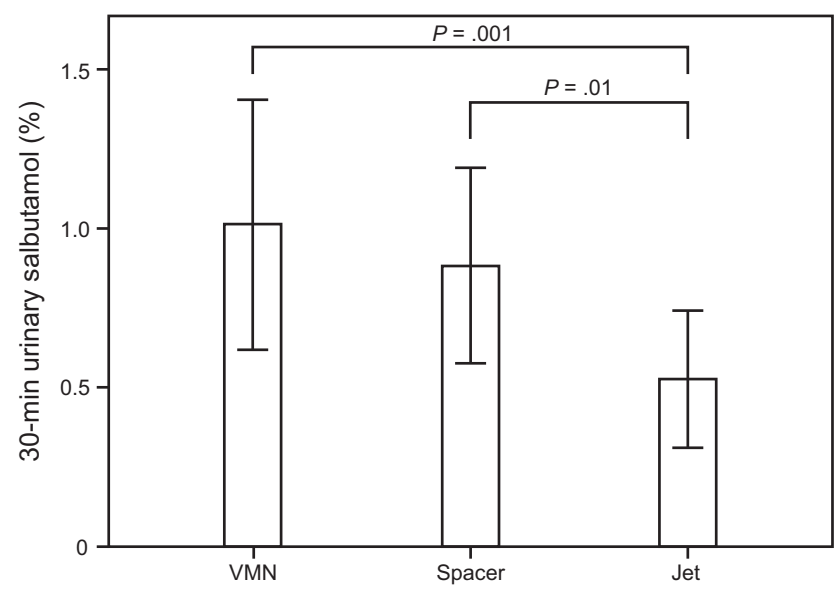

Fig. 4. Percentage of the urinary salbutamol amount (mean \pm SD) excreted $30 \mathrm{~min}$ after dosing by a different aerosol generator. $\mathrm{VMN}=$ vibrating mesh nebulizer.

\section{Ex Vivo Filters}

The fate of the aerosolized drug during the ex vivo study is illustrated in Table 1 and Figure 6. The amount of drug deposited on the filter provided important information on how much of the administered dose would be available to a patient at the cannula opening. The large spacer with pMDI and vibrating mesh nebulizer had the highest percentage, followed by the vibrating mesh nebulizer with the spacer and jet nebulizer (Fig. 6).

\section{Discussion}

Severe hypoxia is a harmful condition that can result in cardiorespiratory failure, irreversible organ damage, or even death if it persists for $>2-3 \mathrm{~min} .{ }^{27}$ Many COPD patients with hypoxemia receive oxygen during exacerbations. ${ }^{18}$ 


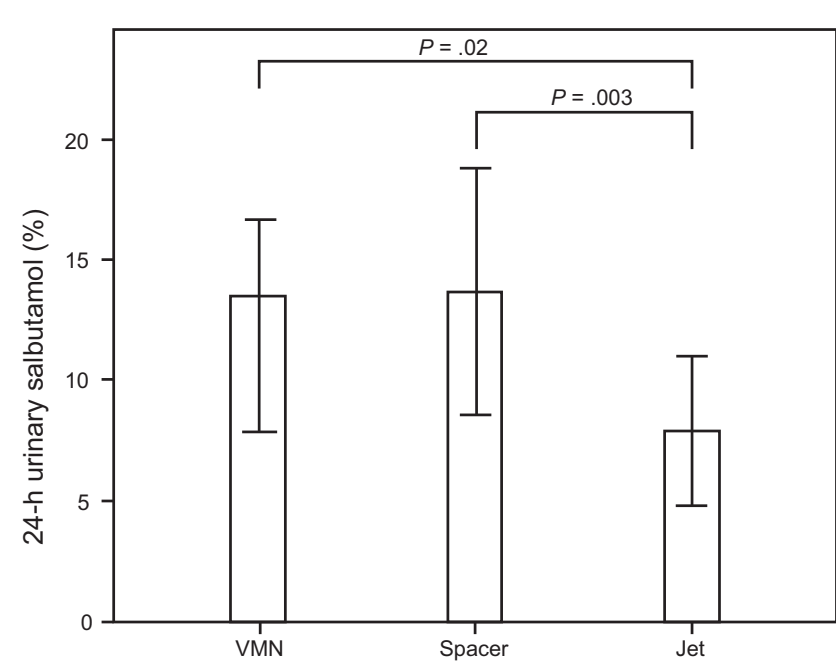

Fig. 5. Percentage of the urinary salbutamol amount (mean \pm SD) pooled at $24 \mathrm{~h}$ after dosing by a different aerosol generator. VMN $=$ vibrating mesh nebulizer.

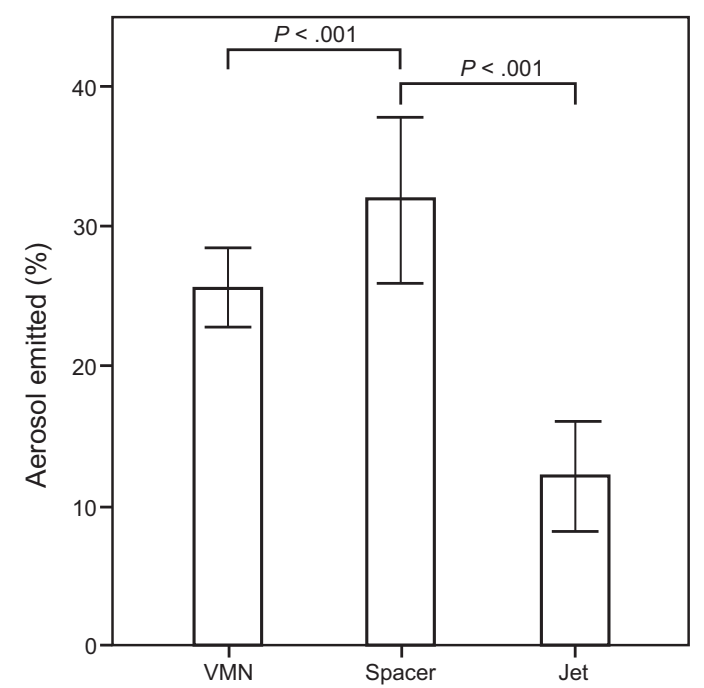

Fig. 6. Percentage of the salbutamol amount (mean \pm SD) deposited on the ex vivo filter (\% aerosol emitted) by different aerosol generator. $\mathrm{VMN}=$ vibrating mesh nebulizer.

This study examined aerosol delivery via either a vibrating mesh nebulizer, a pMDI/vibrating mesh nebulizer combined with a spacer, or a jet nebulizer via a HFNC breathing circuit in COPD subjects with a low oxygen flow $(5 \mathrm{~L} / \mathrm{min})$. We found that the amount of aerosol delivered to the lungs (urinary salbutamol excretion percentage $30 \mathrm{~min}$ post-inhalation) was approximately the same, whether delivered by a vibrating mesh nebulizer connected by a T-piece with or without the spacer $(\sim 1 \%$ nominal dose difference), whereas only half that amount $(\sim 0.5 \%)$ was delivered to lungs by the jet nebulizer. This result is comparable to previously reported findings. ${ }^{16,28}$
Similarly, vibrating mesh nebulizer delivery resulted in approximately the same amount of the nominal dose of salbutamol absorbed systemically (urinary salbutamol excretion percentage $24 \mathrm{~h}$ post-inhalation) using a T-piece connection or a spacer setup $(\sim 13 \%)$, whereas only about half that amount $(\sim 8 \%)$ was absorbed systemically when delivered by jet nebulizer.

The actual differences between the vibrating mesh nebulizer and the jet nebulizer used in this study were similar to many different studies in different settings. ${ }^{29,30,31-42}$ Some studies recommended diluting the respiratory solution in the nebulization chamber of the jet nebulizer to overcome its low aerosol delivery. Even with dilution, however, the jet nebulizer still delivered a lower amount of aerosol compared to the vibrating mesh nebulizer. ${ }^{31,43,44}$

Our findings are lower but comparable to those observed by Réminiac et al, ${ }^{19}$ who evaluated aerosol delivery via vibrating mesh nebulizer with a T-piece at 3 different flows $(2,4$, and $8 \mathrm{~L} / \mathrm{min})$ or a jet nebulizer at $8 \mathrm{~L} / \mathrm{min}$ in both the macaque and Sophia anatomical infant nose-throat models, which represent a full-term neonate and a 9 monthold infant, respectively. They demonstrated using scintigraphic deposition that, at lower flows (ie, 2 and $4 \mathrm{~L} / \mathrm{min}$ ), the vibrating mesh nebulizer used resulted in higher lung deposition in both models compared to the jet nebulizer used at $8 \mathrm{~L} / \mathrm{min} .{ }^{19}$ One possible reason for the variation may be the difference in the methods of drug quantification used in both studies. The urinalysis method that we used indicates the effective lung dose (ie, the drug fraction cleared from lungs by absorption into the bloodstream), whereas the scintigraphic method determines this fraction in addition to that eliminated by mucociliary clearance in the lungs. ${ }^{20}$ Additionally, differences in target populations, nebulizer positions within the HFNC circuit, and experimental setups could result in such variation.

Rabea et al ${ }^{17}$ evaluated aerosol delivery with 3 types of vibrating mesh nebulizer (ie, Aerogen Pro, Aerogen Solo, and NIVO nebulizers) in subjects with COPD treated for exacerbation using NIV with standard recovery parameters. The authors demonstrated that $0.88 \%, 0.83 \%$, and $0.94 \%$ of the nebulizer charge, respectively, were recovered from urinary salbutamol excretion 30 min post-inhalation, and $14.8 \%, 13.9 \%$, and $14.7 \%$ were recovered from urinary salbutamol excretion $24 \mathrm{~h}$ post-inhalation, respectively. Hassan et a ${ }^{21}$ evaluated aerosol delivery with the Aerogen Pro vibrating mesh nebulizer and a sidestream jet nebulizer using NIV in subjects with COPD and observed that $1.1 \%$ and $0.7 \%$ of the nebulizer charge was recovered from urinary salbutamol excretion $30 \mathrm{~min}$ post-inhalation, respectively, and $13.7 \%$ and $8.2 \%$ from urinary salbutamol excretion $24 \mathrm{~h}$ post-inhalation, respectively. We obtained results similar to those reported by Rabea et $\mathrm{al}^{17}$ and Hassan et al, ${ }^{42}$ which highlights relative pulmonary delivery and systemic absorption, respectively. 
Previously, no measurable difference in pulmonary dose delivery or systemic absorption was observed when the same inhalation devices were combined with either a HFNC system or NIV in subjects with COPD. ${ }^{34,39,42,45}$ Although those studies were done using the same urinary salbutamol pharmacokinetic technique, they were performed on different subjects, which adds more variables to those results. Hence, further comparisons between aerosol delivery in HFNC and NIV within the same patient populations are required.

Sarhan et $\mathrm{al}^{22}$ evaluated aerosol delivery with a vibrating mesh nebulizer in healthy subjects and observed that $\sim 2 \%$ of the nebulizer charge was recovered from urinary salbutamol excretion 30 min post-inhalation, and $\sim 18 \%$ was recovered from urinary salbutamol excretion $24 \mathrm{~h}$ post-inhalation. The lower delivery by the vibrating mesh nebulizer in subjects with COPD in our study, as well as the findings in Rabea et al and Hassan et al, ${ }^{34,42}$ compared to the findings in Sarhan et $\mathrm{al}^{22}$ in healthy subjects could be due to diminishing lung function in subjects with COPD compared to healthy subjects.

The results of our study are similar to our previous bench study, ${ }^{26}$ with the exception that the vibrating mesh nebulizer was used with a spacer, which demonstrated better dosing than how it was used in the in vitro study. ${ }^{26}$ This equipment combination resulted in approximately the same pulmonary deposition as the vibrating mesh nebulizer with a T-piece compared to the lower emitted dose in the in vitro study. ${ }^{26}$ The 2 preliminary pMDI puffs delivered when using the large spacer prior to vibrating mesh nebulizer delivery, as recommended by the manufacturer, could account for this difference because it probably causes an initial bronchodilator effect, ${ }^{40,47}$ increasing the lung deposition of salbutamol and consequently obtaining comparable results with a T-piece. ${ }^{24}$ However, the insignificant difference for urinary salbutamol excretion percentage 30 min post-inhalation and urinary salbutamol excretion percentage $24 \mathrm{~h}$ post-inhalation between the T-piece and the T-piece with spacer does not encourage the incorporation of this method as a new practice in nasal cannulamediated aerosol delivery. However, the ex vivo element of this study showed that the vibrating mesh nebulizer with a spacer resulted in higher salbutamol deposition on the filter than both the vibrating mesh nebulizer with a T-piece and the jet nebulizer $(P<.001)$. These results differed from the relative pulmonary deposition (urinary salbutamol excretion percentage $30 \mathrm{~min}$ post-inhalation) and systemic absorption (urinary salbutamol excretion percentage $24 \mathrm{~h}$ post-inhalation). This difference could be due to the position of the ex vivo filter, which was between the nebulizer and the opening of the nasal cannula, representing the amount of aerosol available to enter the respiratory system. The different dose between the in vivo and the ex vivo setups could be attributed to the small diameter of the cannula compared to the inserted spacer and the Tpiece, which may preferentially allow only smaller particles to pass through it and reach the subject. If so, the use of the large spacer in a HFNC circuit would be of little benefit in conserving aerosol compared to the normal $\mathrm{T}$ piece of the nebulizer.

When both a T-piece and a large spacer are utilized in either invasive ventilation or NIV, larger drug losses are reported during aerosol delivery, which results in a lower drug fraction delivered to the lungs (ie, $1-10 \%$ among adults in HFNC therapy). ${ }^{30,38,48}$ To reduce aerosol losses in HFNC circuits from $50-70 \%$ to $<20 \%$, newer methods such as a condensational growth technique could be applied for the delivery of aerosols with submicrometer-sized droplets, which have proven high efficiency in delivering inhaled aerosols to the lungs within HFNC systems, rather than conventional micrometer-sized aerosols. ${ }^{25,29}$ However, validation of the condensational growth technique in animal and human models is needed before clinical use. ${ }^{30,35}$

In addition, HFNC improves heating and humidification of gas compared to NIV and can improve mucociliary clearance, decrease mucus viscosity, and thus facilitate expectoration in critically ill patients. ${ }^{27,34}$ Lung function and quality of life measurements could be improved, in addition to significant reduction in exacerbation frequencies and exacerbation days. ${ }^{36}$ Similarly, patient tolerance would likely be improved with continuous or prolonged nebulized aerosols. ${ }^{19}$ Nevertheless, long-term intranasal drug delivery and its effect on the mucosal lining anatomy and physiology, in addition to ciliary function, requires more scrutiny. ${ }^{28}$

Edwards et a ${ }^{31}$ compared the effect of oxygen or air as the driving gases in nebulizers on $\mathrm{P}_{\mathrm{aCO}_{2}}$ in subjects with COPD receiving salbutamol. The air-driven nebulizer tested did not affect $\mathrm{P}_{\mathrm{aCO}}$, whereas a significant rise in $\mathrm{P}_{\mathrm{aCO}}$, was noticed in subjects with baseline hypercapnia and not in the normocapnic COPD subjects. This effect was not investigated in our study, but such an increase was not expected because subjects involved in this study had no previous history of hypercapnia.

Overall, combining aerosol delivery with HFNC therapy is a desirable medical practice and is considered to be advantageous for patients and health care providers instead of the frequent treatments administered with a mouthpiece. $^{3}$

In this study, salbutamol delivered at low oxygen flow through a HFNC circuit improved aerosol delivery to subjects compared to delivery data from previous bench studies. ${ }^{16,18,19}$ However, at low flows, some physiological benefits of using higher flows, such as nasopharyngeal deadspace washout and decreased work of breathing through inspiratory flow matching of the patient, will be diminished. ${ }^{27}$ However, titrating the flow back to higher levels after drug nebulization could overcome this problem. 


\section{Aerosol Delivery Through an HFNC Circuit}

Using low-flow oxygen is supported by Austin et al, ${ }^{32}$ who reported that subjects with COPD exacerbation given titrated oxygen in the pre-hospital setting rather than high flows to obtain $\mathrm{P}_{\mathrm{aO}}$ saturation falling in the range of 88$92 \%$ had a significant reduction in respiratory acidosis and mortality rates. In this way, hypoxemia could be corrected in COPD patients by the use of titrated oxygen while simultaneously avoiding unnecessarily high $\mathrm{P}_{\mathrm{aO}} \cdot{ }^{33}$

Our study has several limitations. The lower significance difference found here in relative pulmonary deposition (urinary salbutamol excretion percentage $30 \mathrm{~min}$ post-inhalation) and systemic absorption (urinary salbutamol excretion percentage $24 \mathrm{~h}$ post-inhalation) compared to our previous in vitro result was expected because the coefficient of variation for urinary salbutamol was reported to be relatively high, as seen in our results. This finding and the expected 35\% intra- and inter-patient variability contributed to the lack of statistical significance in our small patient population. However, our pilot data can now be used to appropriately size future studies.

\section{Conclusion}

Aerosol delivery by nebulizers can be efficiently combined with an adult HFNC circuit using low-flow oxygen in patients with COPD and a history of exacerbations. After treatment delivery, titrating the oxygen flow back to obtain the targeted arterial oxygen saturation may be a necessary recommendation, but this requires further investigation in clinical settings. The vibrating mesh nebulizer with both a T-piece and large spacer provided higher pulmonary drug delivery than the traditionally used jet nebulizer when combined with oxygen therapy within a HFNC circuit. However, no significant benefit of using the large spacer with the combined pMDI-nebulizer delivery was found.

\section{ACKNOWLEDGMENTS}

Dr James B Fink provided his aerosol science expertise for the development of the manuscript. Professor Brendan Higgins lent his support in aerosol science expertise and English language editing for the development of the manuscript. Professor Sameh AbdelGhani proofread the manuscript.

\section{REFERENCES}

1. Nedel WL, Deutschendorf C, Rodrigues Filho EM. High-flow nasal cannula in critically ill subjects with or at risk for respiratory failure: a systematic review and meta-analysis. Respir Care 2017;62(1):123132.

2. Sim M, Dean P, Kinsella J, Black R, Carter R, Hughes M. Performance of oxygen delivery devices when the breathing pattern of respiratory failure is simulated. Anaesthesia 2008;63(9):938-940.

3. Papazian L, Corley A, Hess D, Fraser JF, Frat J-P, Guitton C, et al. Use of high-flow nasal cannula oxygenation in ICU adults: a narrative review. Intensive Care Med 2016;42(9):1336-1349.
4. Weg JG, Haas CF. Long-term oxygen therapy for COPD: improving longevity and quality of life in hypoxemic patients. Postgrad Med 1998;103(4):143-155.

5. Gotera C, Lobato SD, Pinto T, Winck J. Clinical evidence on high flow oxygen therapy and active humidification in adults. Rev Port Pneumol 2013;19(5):217-227.

6. Chatila W, Nugent T, Vance G, Gaughan J, Criner GJ. The effects of high-flow vs low-flow oxygen on exercise in advanced obstructive airways disease. Chest 2004;126(4):1108-1115.

7. Ward JJ. High-flow oxygen administration by nasal cannula for adult and perinatal patients. Respir Care 2013;58(1):98-122.

8. Bräunlich J, Beyer D, Mai D, Hammerschmidt S, Seyfarth H-J, Wirtz H. Effects of nasal high flow on ventilation in volunteers, COPD and idiopathic pulmonary fibrosis patients. Respiration 2013; 85(4):319-325.

9. Lee CC, Mankodi D, Shaharyar S, Ravindranathan S, Danckers M, Herscovici $\mathrm{P}$, et al. High flow nasal cannula versus conventional oxygen therapy and non-invasive ventilation in adults with acute hypoxemic respiratory failure: a systematic review. Respir Med 2016; 121:100-108.

10. Bräunlich J, Köhler M, Wirtz H. Nasal high flow improves ventilation in patients with COPD. Int J Chron Obstruct Pulmon Dis 2016; 11:1077-1085.

11. Tian G, Hindle M, Longest PW. Targeted lung delivery of nasally administered aerosols. Aerosol Sci Technol 2014;48(4):434-449.

12. Frat J-P, Thille AW, Mercat A, Girault C, Ragot S, Perbet S, et al. High-flow oxygen through nasal cannula in acute hypoxemic respiratory failure. N Engl J Med 2015;372(23):2185-2196.

13. Abdelrahim M, Plant P, Chrystyn $H$. The relative lung and systemic bioavailability of terbutaline following nebulisation in non-invasively ventilated patients. Int J Pharm 2011;420(2):313-318.

14. Sztrymf B, Messika J, Bertrand F, Hurel D, Leon R, Dreyfuss D, et al. Beneficial effects of humidified high flow nasal oxygen in critical care patients: a prospective pilot study. Intensive Care Med 2011;37(11):1780-1786.

15. Hindle M, Chrystyn H. Determination of the relative bioavailability of salbutamol to the lung following inhalation. Br J Clin Pharmacol 1992;34(4):311-315.

16. ElHansy MHE, Boules ME, El-Essawy AFM, Al-Kholy MB, Abdelrahman MM, Said ASA, et al. Inhaled salbutamol dose delivered by jet nebulizer, vibrating mesh nebulizer and metered dose inhaler with spacer during invasive mechanical ventilation. Pulm Pharmacol Ther 2017;45:159-163.

17. Rabea H, Ali AMA, Salah Eldin R, Abdelrahman MM, Said ASA, Abdelrahim ME. Modelling of in-vitro and in-vivo performance of aerosol emitted from different vibrating mesh nebulisers in noninvasive ventilation circuit. Eur J Pharm Sci 2017;97:182-191.

18. Teixeira C, Savi A, Tonietto TF. Influence of $\mathrm{FIO}_{2}$ on $\mathrm{PaCO}_{2}$ during noninvasive ventilation in patients with COPD. Respir Care 2014; 59(7):e106-e107.

19. Réminiac F, Vecellio L, Heuzé-Vourc'h N, Petitcollin A, Respaud R, Cabrera M, et al. Aerosol therapy in adults receiving high flow nasal cannula oxygen therapy. J Aerosol Med Pulm Drug Deliv 2016; 29(2):134-141.

20. Chrystyn H. Methods to identify drug deposition in the lungs following inhalation. Br J Clin Pharmacol 2001;51(4):289-299.

21. Hassan A, Salah Eldin R, Abdelrahman MM, Abdelrahim ME. In-vitro/in-vivo comparison of inhaled salbutamol dose delivered by jet nebulizer, vibrating mesh nebulizer and metered dose inhaler with spacer during non-invasive ventilation. Exp Lung Res 2017;43(1):19-28.

22. Sarhan RM, Elberry AA, Abdelwahab NS, Rabea H, Salem MN, Abdelrahim MEA. Effect of a nebulizer holding chamber on aerosol delivery. Respir Care 2018;63(9):1125-1131. 


\section{Aerosol Delivery Through an HFNC Circuit}

23. Longest PW, Tian G, Hindle M. Improving the lung delivery of nasally administered aerosols during noninvasive ventilation: an application of enhanced condensational growth (ECG). J Aerosol Med Pulm Drug Deliv 2011;24(2):103-118.

24. Harb HS, Elberry AA, Rabea H, Fathy M, Abdelrahim MEA. Is Combihaler usable for aerosol delivery in single limb non-invasive mechanical ventilation? J Drug Deliv Sci Technol 2017;40:28-34.

25. Golshahi L, Longest PW, Azimi M, Syed A, Hindle M. Intermittent aerosol delivery to the lungs during high-flow nasal cannula therapy. Respir Care 2014;59(10):1476-1486.

26. Madney YM, Fathy M, Elberry AA, Rabea H, Abdelrahim MEA. Nebulizers and spacers for aerosol delivery through adult nasal cannula at low oxygen flow rate: an in-vitro study. J Drug Deliv Sci Technol 2017;39:260-65.

27. Spoletini G, Alotaibi M, Blasi F, Hill NS. Heated humidified highflow nasal oxygen in adults. Chest 2015;148(1):253-261.

28. Quraishi M, Jones N, Mason J. The nasal delivery of drugs. Clin Otolaryngol Allied Sci 1997;22(4):289-301.

29. Golshahi L, Tian G, Azimi M, Son Y-J, Walenga R, Longest PW, et al. The use of condensational growth methods for efficient drug delivery to the lungs during noninvasive ventilation high flow therapy. Pharm Res 2013;30(11):2917-2930.

30. Hess DR. Aerosol therapy during noninvasive ventilation or highflow nasal cannula. Respir Care 2015;60(6):880-893.

31. Edwards L, Perrin K, Williams M, Weatherall M, Beasley R. Randomised controlled crossover trial of the effect on $\mathrm{PtCO} 2$ of oxygendriven versus air-driven nebulisers in severe chronic obstructive pulmonary disease. Emerg Med J 2012;29(11):894-898.

32. Austin MA, Wills KE, Blizzard L, Walters EH, Wood-Baker R Effect of high flow oxygen on mortality in chronic obstructive pulmonary disease patients in prehospital setting: a randomised controlled trial. BMJ 2010;341:c5462.

33. Pilcher J, Weatherall M, Perrin K, Beasley R. Oxygen therapy in acute exacerbations of chronic obstructive pulmonary disease. Expert Rev Respir Med 2015;9(3):287-293.

34. Rea H, McAuley S, Jayaram L, Garrett J, Hockey H, Storey L, et al. The clinical utility of long-term humidification therapy in chronic airway disease. Respir Med 2010;104(4):525-533.

35. Berlinski A. Pediatric aerosol therapy. Respir Care 2017;62(6):662677.

36. Nishimura M. High-flow nasal cannula oxygen therapy in adults: physiological benefits, indication, clinical benefits, and adverse effects. Respir Care 2016;61(4):529-541.

37. Abdelrahim ME, Plant $\mathrm{P}$, Chrystyn H. In-vitro characterisation of the nebulised dose during non-invasive ventilation. J Pharm Pharmacol 2010;62(8):966-972.

38. ElHansy MHE, Boules ME, Farid H, Chrystyn H, El-Maraghi SK, Al-Kholy MB, et al. In vitro aerodynamic characteristics of aerosol delivered from different inhalation methods in mechanical ventilation. Pharm Dev Technol 2017;22(6):844-849.

39. Mohsen M, Elberry AE, Salah Eldin A, Hussein RR, Abdelrahim EM. Effects of Heat and Humidification on Aerosol Delivery during Auto-CPAP noninvasive Ventilation. Archives of Pulmonology and Respiratory Care 2017;3(1):11-15.

40. Harb HS, Elberry AA, Rabea H, Fathy M, Abdelrahim MEA. Is Combihaler usable for aerosol delivery in single limb non-invasive mechanical ventilation? J Drug Deliv Sci Technol 2017;40:28-34.
41. Hassan A, Rabea H, Hussein RRS, Salah Eldin R, Abdelrahman MM, Said ASA, et al. In-vitro Characterization of the Aerosolized Dose During Non-Invasive Automatic Continuous Positive Airway Pressure Ventilation. Pulm Ther 2016;2(1):115-126.

42. Hassan A, Salah Eldin R, Abdelrahman MM, Abdelrahim ME. Invitro/in-vivo comparison of inhaled salbutamol dose delivered by jet nebulizer, vibrating mesh nebulizer and metered dose inhaler with spacer during non-invasive ventilation. Exp Lung Res 2017;43(1): 19-28.

43. Saeed H, Ali AMA, Elberry AA, Salah Eldin A, Rabea H, Abdelrahim MEA. Modeling and optimization of nebulizers' performance in non-invasive ventilation using different fill volumes: comparative study between vibrating mesh and jet nebulizers. Pulm Pharmacol Ther 2018:(in press).

44. Saeed H, Mohsen M, Salah Eldin A, Elberry AA, Abdelwahab NS, Hussein RRS, et al. Effects of fill volume and humidification on aerosol delivery during single limb non-invasive ventilation. Respir Care 2018; (In Press)

45. Hussein RRS, M. A. Ali A, Salem HF, Abdelrahman MM, Said ASA, Abdelrahim MEA. In vitro/in vivo correlation and modeling of emitted dose and lung deposition of inhaled salbutamol from metered dose inhalers with different types of spacers in noninvasively ventilated patients. Pharm Dev Technol 2017;22(7):871-880.

46. Sarhan RM, Elberry AA, Abdelwahab NS, Rabea H, Salem MN, Abdelrahim MEA. The effect of holding chamber, as add on device for nebulizers, on aerosol delivery. Respir Care 2018;(In Press)

47. Boukhettala N, Porée T, Diot P, Vecellio L. In vitro performance of spacers for aerosol delivery during adult mechanical ventilation. J Aerosol Med Pulm Drug Deliv 2015;28(2):130-136.

48. Golshahi L, Longest PW, Azimi M, Syed A, Hindle M. Intermittent aerosol delivery to the lungs during high-flow nasal cannula therapy. Respir Care 2014;59(10):1476-1486.

49. Golshahi L, Tian G, Azimi M, Son Y-J, Walenga R, Longest PW, et al. The use of condensational growth methods for efficient drug delivery to the lungs during noninvasive ventilation high flow therapy. Pharm Res 2013;30(11):2917-2930.

50. Berlinski A. Pediatric Aerosol Therapy. Respir Care 2017;62(6): 662-677.

51. Rea H, McAuley S, Jayaram L, Garrett J, Hockey H, Storey L, et al. The clinical utility of long-term humidification therapy in chronic airway disease. Respir Med 2010;104(4):525-533.

52. Spoletini G, Alotaibi M, Blasi F, Hill NS. Heated humidified highflow nasal oxygen in adults. Chest 2015;148(1):253-261.

53. Quraishi M, Jones N, Mason J. The nasal delivery of drugs. Clin Otolaryngol Allied Sci 1997;22(4):289-301.

54. Edwards L, Perrin K, Williams M, Weatherall M, Beasley R. Randomised controlled crossover trial of the effect on $\mathrm{PtCO} 2$ of oxygendriven versus air-driven nebulisers in severe chronic obstructive pulmonary disease. Emerg Med J 2012;29(11):894-898.

55. Austin MA, Wills KE, Blizzard L, Walters EH, Wood-Baker R. Effect of high flow oxygen on mortality in chronic obstructive pulmonary disease patients in prehospital setting: Randomised controlled trial. Bmj 2010;341:c5462

56. Pilcher J, Weatherall M, Perrin K, Beasley R. Oxygen therapy in acute exacerbations of chronic obstructive pulmonary disease. Expert Rev Respir Med 2015;9(3):287-293. 